\title{
On the Causes of Mathematics Learning Anxiety and Countermeasures from Students' Perspectives
}

\author{
Angyang Liu \\ University of Science and Technology of China \\ Hefei, China 230000
}

\begin{abstract}
Students tend to develop anxiety when studying. The mathematics learning anxiety is a special subject anxiety, which will Interfere with students' academic performance, damage students' mental health and hinder students' social developments.This article has analyzed the subjective and objective factors attributing to the mathematics learning anxiety in mathematics learning process, stated the negative impacts of the anxiety and put forward some countermeasures to overcome mathematics learning anxiety.
\end{abstract}

Keywords-mathematics learning anxiety; causes; countermeasures; perspectives

\section{INTRODUCTION}

Mathematics learning anxiety is a special anxiety which features a series of abnormal physiological, psychological and behavioral performance. The main symptoms are: having no confidence in learning mathematics well, feeling too much pressure, feeling over strained everyday, having poor selfcontrol and bad focus when taking mathematics classes or reading mathematics books, keeping confusing mathematics knowledge points with poor memory, not knowing how to solve mathematics problems and always making mistakes though having a clear mind of methods, feeling extremely worried when taking mathematics exams and always wanting to quit the mathematics exams.

\section{CAUSES OF THE MATHEMATICS LEARNING ANXIETY}

There are many factors which may lead to mathematics learning anxiety. The main causes can be classified into the following aspects: the nature of mathematics, students, teachers and students' parents.

\section{A. The Causes from the Nature of Mathematics}

Mathematics is one of the most important subjects and the most difficult ones for students as well. On one hand, mathematics is not only a compulsory course for students going to higher grade, it is also the basis of other discipline. Their prospect would be seriously impacted if students can not study mathematics well or present a good performance in mathematics exams, which will create some pressure to students. On the other hand, mathematics is a very difficult subject because of its nature of preciseness and abstractness. In mathematics, current formulas, symbols and theorems have been formed in a standard logic way through a long history of development. But during the development process, other steps, such as intuition, guessing and trial and error, haven't been recorded or they have been omitted for editing reasons, which give rise to more obstacles to students in their understanding mathematics knowledge and developing mathematics thinking. In addition, the specific language used in mathematics helps increase the difficulty in mathematics learning. Language used in mathematics is not visualized and colloquial language. Most part of the language is newly introduced definition, while some part is borrowed from the living language vocabulary which presents totally different meanings. These language symbols of preciseness and abstractness are rarely intensified in other fields. The features of mathematics make students develop a special emotional experience--fearing mathematics and developing mathematics learning anxiety.

\section{B. Causes from Students}

There are various causes leading to students' mathematics learning anxiety, including students' characters, interests in mathematics study and mathematics knowledge and abilities.

1) Characters: The students' personality factors have a certain impact on mathematics anxiety. Researches have shown that students who have the self-abasement and introverted personality are more sensitive to study anxiety and tend to develop mathematics learning anxiety. Outgoing students have more opportunities to communicate and express their ideas in mathematical activities and therefore have more sense of achievement. So outgoing students who have stable emotion can be more focused on their mathematics than students who are introverted.

2) Factors from Interests in study: Researches have shown that students' external motivations such as motivations for high scores and situational environment have positive relationship with mathematics learning anxiety. Internal motivations such as motivations for interests and selffulfillment have negative relationship. So if students' study motivations are originated from love and interests in mathematics, they are willing to study mathematics, get involved in mathematical activities and feel little worried about mathematics. If the students study mathematics just to get other people's recognition and admiration or just want to get a good score in mathematics study, they tend to develop mathematics learning anxiety and gradually lose interests in mathematics study, keeping silent in mathematical activities. 
3) Factors from mathematics knowledge and abilities: Generally speaking, the solider mathematics knowledge and better mathematics abilities students possess, the more confidence students have in their mathematics study. These students are more willing to study mathematics with high enthusiasm. They will speak out and take part in class activities with little anxiety. On the contrary, those students with poor mathematics always have psychological burden since they fear that they can not demonstrate better performance than other classmates. These students develop anxieties since they fear that their mathematics teachers will not accept them.

\section{Factors from Mathematics Teachers}

In traditional mathematics classes, mathematics teachers would at any moment ask students to answer questions orally or go to the stage of the classroom to write answers on the blackboard. Although students with poor mathematics knowledge or little preparation before class feel difficult to fulfill the task, they have to do what their mathematics teachers ask them to do, which make them worried and anxious. If a strained relationship between teachers and students exist, hostility, precaution and anxiety will grow in students who imagine that teachers ask questions to embarrass them. Mathematics teachers' improper language and actual behavior will also bring anxiety to students. For instance, some mathematics teachers will mock and physically punish students who can not answer or give wrong answers. Teachers' covert behavior also can cause anxiety to students. If mathematics teachers favor those students with good mathematics performance, often praise excellent students, always imply that only smart students can solve challenging mathematics problems, their behaviors, though covert, can be as harmful to students as overt ones. Since mathematics study needs continual and systematic thinking, any terrified and upset mental state will have negative impact on mathematics thought.

\section{Factors from Students' Parents}

Keeping the idea that good study performance means good job in the future, parents would blindly urge students to study hard. Some parents even take exam scores as the only standard to judge whether students have studied hard in the school or chatted and played games on the internet. They do not care about students' confusion, failure or setback. Though sometimes students wanted to get a good mark in the exam to repay their parents, they failed because of their weak mathematics abilities. The contradiction between parents' too high expectation and students' low mathematics abilities will emerge. Parents' high expectation can not change students' pressure into drive, on the contrary, it will make students more and more dislike mathematics study and exam than before.

\section{THE NEGATIVE IMPACTS OF MATHEMATICS LEARNING} ANXIETY

Though many people think that suitable anxiety may urge students to work harder and learn more, most experts imagine that the negative impacts brought by anxiety over weigh the positive impacts and mathematics learning anxiety would usually cause harmful impacts.

\section{A. Mathematics Learning Anxiety can Get Students Develop Passive Ideas of Mathematics Learning}

Students with mathematics learning anxiety usually fear mathematics classes, do not have interests in mathematics, regard mathematics classes as a kind of burden and torture. Some of these students do not concentrate on the classes, they always sleep in the class, send short messages with cell phones, read books unrelated with mathematics, skip mathematics classes. Their mathematics performance does not show any improvement and some students even drop out of school or fail to go up to the higher grade. Some students with mathematics learning anxiety fear mathematics exams. Several days before the exam, they feel upset, can not sleep at night, have no appetite for foods, have bad memory, have absent mind. Some students may have a headache or stomachache. During the exam, some students' limbs may shiver and their whole body may tremble in cold sweat. Their hearts beat faster and their attention can not be paid to the exam contents. They usually suddenly forget the mathematics knowledge and make more mistakes in the exam.

\section{B. Mathematics Learning Anxiety can Have a serious Impacts on Students' Positive Self Recognition}

Mathematics learning anxiety can lower students' self assessment and self-consciousness and affect their correct self awareness. The anxiety will damage students' personality structure. These students always feel timid and shy. Extreme anxiety can easily disperse or stop students' attention, interfere with their process of memory and disorganize their thinking process. In addition, mathematics learning anxiety will lower students' mental efficiency, bring annoyance to these students, make their emotion unstable and restless. Some students with mathematics learning anxiety may think that only those very intelligent students can learn mathematics well. So when they met difficulties in mathematics learning, they will develop a sense of failure and incompetence. All the above things will undoubtedly present a heavy strike on these students' self recognition.

\section{Mathematics Learning Anxiety can Threaten Students' Health}

When meeting difficulties in mathematics learning, many students with mathematics learning anxiety will have such physiological responses as fast heart beat, sweating, feeling a little dizzy, having a parched mouth and a scorched tongue and having a dull thinking and even a blank mind. Mathematics learning anxiety can lead to the failure of function of brain neural activity of excitement and inhibition, cause the formation of various types of neurosis, one of which is neurasthenia, commonly seen among students. Mathematics learning anxiety keeps the sympathetic nervous system in a state of excitement and if this state lasts for a long time it can cause cardiovascular disorders. Eventually arrhythmia, high blood pressure and coronary heart disease will happen. Thus, impact on physical and mental health of mathematics learning anxiety is huge. Anxiety will have many harmful effects after a 
long period of time. So excessive mathematics learning anxiety must be corrected as early as possible, so as to promote students' development of physical and mental health.

\section{SOME SugGestions On OVERCOMING MAthEMATICS LEARNING ANXIETY}

\section{A. Suggestions to Students}

1) Learn to positively attribute: It is very important for students to learn how to analyze the cause of success and failure. If students attribute the difficulties to their low ability, they may lose confidence in mathematics and will lose motivation to continue their mathematics study and develop their potential. So students will never look down upon themselves in mathematics. They can reflect on their learning methods and the degree of their efforts. If students master scientific learning methods and put more effort, their performance in mathematics will be improved. It will help to boost their confidence in mathematics learning if they attribute their success to their hard word and ability.

2) Learn to set reasonable goals: Since the success of mathematics learning usually needs more effort to achieve, if students always set too high mathematics learning goals and often suffer setbacks, they will gradually reduce their mathematics self-efficacy in the setbacks. High expectation and low recognition and low self-efficacy will conflict, inevitably leading to mathematics learning anxiety. Therefore, students in mathematics study should consider their own conditions before setting learning goals, which can be achieved after a period of hard work. Only by so doing, they can gain success and gradually enhance their mathematics self-efficacy.

3) Cultivate interest in mathematics study: Students should pay attention to cultivating the intrinsic interest in mathematics learning, because interest is the best teacher and intrinsic interest is the most powerful and lasting driving force to learn math. If students have the interest in learning, they will no longer haggle over every ounce for a good or bad performance in mathematics and the evaluation of others.They will have more long-term learning goals. When meeting temporary difficulties in mathematics learning, they will not develop anxiety easily.

4) Listen to the teacher's advice and develop the confidence to learn mathematics well: Students with too high mathematics learning anxiety tend to think that they don't have the conditions to learn mathematics well. These students lack of confidence, can't make an objective and fair evaluation on their own. The whole process of mathematics study is always conducted under a depressive mood which will naturally hinder the mathematics learning progress and affect the efficiency of learning mathematics. To solve these problems, students should humbly accept guidance when the teacher help the students analyze their advantages or disadvantages. It is inevitable for us students to make mistakes and have unsatisfactory performance in the classroom. It is completely impossible to understand and grasp the whole contents mathematics our mathematics teachers present. We should also accept the teacher's criticism and instruction. All in all, we students must form a positive and optimistic attitude, enhance our self-confidence, so as to eliminate mathematics learning anxiety from psychological aspect.

\section{B. Suggestions to Parents}

In the process of students' learning mathematics, parents play a vital role. Most parents are not very adept in mathematics. It is not an easy thing to tutor students mathematics. Parents should cultivate children's interest and habit of learning mathematics, arouse their enthusiasm of mathematics study. Parents should correctly treat the mathematics test scores. Parents should always find out the progress students have made. Do not always compare their children with "outstanding students". They should always encourage students and get concerned about the students' mathematics learning. Parents should not criticize their children when they have mathematics problems. Criticizing, beating, scolding and mocking can do nothing good for the students. Parents should help students cultivate their mathematics learning perseverance and the ability to withstand the difficulties and setbacks. Parents should create a good family environment, such as the material conditions, learning environment, etc. In addition, parents must set up a good example to their children. First of all, parents should not keep prejudice thoughts, letting their children develop the "only smart people can learn mathematics" idea. Otherwise these children will lose confidence of mathematics study. Secondly, parents should treat children's mathematics performance with a reasonable expectation according to their children's actual situations. Parents should have proper expectation. Too high expectation from children will cause them anxious. Finally, parents should understand and support their children, create warm family atmosphere and learning environment, timely realize the problems children may have in their mathematics learning process and help them solve these problems.

\section{Suggestions to Mathematics Teachers}

1) Help students establish a clear knowledge structure: When teaching mathematics, mathematics teachers should focus on students' understanding instead of only teaching them problem solving methods. Mathematics teachers should help students understand the ins and outs of mathematics concepts and help students consolidate the basic knowledge and basic skills to establish clear mathematical knowledge structure through appropriate training, so that the students can completely comprehend and digest what they have been taught.

2) Make the mathematics classroom full of fun: Mathematics teachers when teaching must be good at revealing the beauty of mathematics to infect students with love and interests. In mathematics classes, they should guide students to feel the beauty of mathematics, form the positive experience of mathematics learning. By solving seemingly complex mathematical problems in several algebraic 
expressions after analyzing and summarizing, teachers can enlighten students. By making things simple and getting a concise answer successfully in the process of problem solving, mathematics teachers can make students feel the joy and success. The natural beauty of mathematics, the natural interpretation and revealing of mathematical mystery will not only affect students, make students interested in mathematics, but also can make mathematics classroom full of fun, avoiding the occurrence of students' anxiety in mathematics learning.

3) Encourage and tolerate students in students' mathematics learning: Teachers should know that since the students' family background, learning environment are different, such differences will naturally be reflected in mathematical ability and mathematics performances. Progress in learning of mathematics can not be expected the same. When students study mathematics, it will be inevitable for them to make some mistakes. Teachers' blind criticism will give students a lot of pressure, increase students' mathematics learning anxiety. So mathematics teachers should keep an encouraging and tolerant attitude towards students. Teachers should not expect all the students to reach the same achievement at the same time. Mathematics teachers should patiently guide students when they make mistakes in mathematics learning so that they will gradually reduce errors and improve their mathematics performances.

\section{REFERENCES}

[1] Cheng Junling. Research summary on learning anxiety[J]. Education theory and practice, 2012, (4): 13

[2] Tan Huijuan. The application of the positive psychology theory on the transformation of poor students in colleges and universities[J]. Educational criticism,2013( 5): 45-47

[3] Li Tingzhi. Approaches to maths teaching[M]. Beijing higher education press.2010.

[4] Zhang Dianyu. Mathematics education research guidance[M].Jiangsu Education Publishing House. 2012.

[5] Zhou Lin, Zhao Wende. Math anxiety related research[J].The Border Economy and Culture, 2013( 7):132-133.

[6] Wu Ning. On non-intelligence education in 21 st century higher education field[J].Chinese higher education, 2011, (9):45-47.

[7] Wang Jianjun. Mathematics learning anxiety countermeasures[J]. Chinese Vocational and Technical Education, 2011,(6):67-69.

[8] Xie MingChu. The prevention and elimination of the mathematics learning anxiety[J]. Journal of Mathematics Education, 2012,(1):43.

[9] Mathematics classroom anxiety and teaching countermeasures[J]. Journal of Fujian normal university, 2014,(4):34-35. 